\title{
A Close Look at Water Scarcity
}

\author{
Jinyi Shen \\ North China Electric Power University, Beijing, 102206 \\ alanncepu@foxmail.com
}

Keywords: Water scarcity; Macro-model; Micro-model; Water shortage

\begin{abstract}
Water shortage problem is increasingly becoming the focus of great concern to everyone in the world. First, we develop two models-Macroscopic Model and Microscopic Model to measure the ability of a region to provide clean water. We calculate the amount of water supply and demand approximately, and we adopt a Macro-Model to measure the water provision ability in a large region. While the Micro-Model concentrates on the dynamic nature of the factors. Then we use the unified criteria and determine the weighs via the AHP, working out an indicator to reflect the ability to provide clean water in a certain region. Second, we pick Beijing for further study. We conclude that the water is heavily overloaded in Beijing, mainly caused by the large population. Finally, our intervention plan is to build a new dam in Beijing. Applying the goal programming, we determine the specific way to build this dam. Our primary goal is to mitigate water scarcity in Beijing, namely improve water availability. Meanwhile, our minor aim is to minimize the investment of this dam projection. Additionally, we analyze the influence on the surrounding areas and the entire water ecosystem.
\end{abstract}

\section{Introduction}

As we all know, water is indispensable to our life and the development of national economy. It is often described as the source of all living things and the lifeblood of agriculture and industry. Without it, nothing could grow and world would become a terrible desert.

With the development of modern industry and the growth of population, water shortage has become a growing concern for government and people all over the world.

Several factors contribute to this issue. On the one hand, water supplies are being consumed by a growing number of heavy industries as well as the increasing population. On the other hand, plenty of rivers and lakes have been polluted. What's more, climate change has made the situations worse. Last but not the least, poor management and lack of infrastructure also limit the availability of clean water.

It is high time for us to do something to prevent it from being worse. In order to solve the problem, several measures can be taken. First, we must economize the use of water resources and practice a recycling policy. Second, stricter laws and regulations should be implemented to protect the limited water resources we have. Finally, more diversion projects should also be used so as to direct the surplus water resources in the Southern Chine to the under-supplied regions. In a word, stronger measures can and should be taken to protect the water resources we have now.

\section{General Model for Water Supply and Demand}

We develop two models to tackle the problem. The Macro-Model is designed to measure the ability of a region to provide clean water to meet the needs of its population, while the Micro-Model concentrates on the dynamic nature of the factors that affect both supply and demand, based on more detailed information about the region we research, such as GDP, population, rainfall etc.

The outcomes of those two approaches show great consistency when applied to a real scenario.

Macro-Model. Usually, we do not know some details in a large area, we can only calculate the amount of water supply and demand approximately, so we adopt a Macro-Model. 
On account of that the ability is closely connected to the relationship between water supply and demand, we count the total amount of both water supply and demand in our model. Afterwards, we introduce a indicator A (ability) to reflect this ability, which is represented as

$$
\text { Ability }=(\text { Demand }- \text { Supply }) / \text { Supply }
$$

We take Australia, Brazil, China, USA, France and South Africa for example.

Step 1. Calculating the amount of water supply

We think that the amount of water supply is determined by annual renewable water resources, freshwater withdrawal and seawater desalination. Ability= (Demand-Supply)/Supply

So the amount of water supply can be represented as

$$
\text { Supply }=\text { Renewable water }+ \text { Freshwater withdrawal }+ \text { Seawater desalination(2) }
$$

With the data, the amount of water supply can be obtained.

Step 2. Calculating the amount of water demand

We consider that the amount of water consumption only includes three sectors: agricultural, industrial and domestic consumption. So as to get the total amount, we sum them up.

Step 3. Counting the indicator A

According to the equation (1), we get Tab.1:

Table 1

\begin{tabular}{|c|c|c|c|c|c|c|}
\hline & Australia & Brazil & China & USA & France & South Africa \\
\hline Ability & 103.9927 & 41.8602 & 406.7956 & 178.6159 & 463.4192 & 609.4006 \\
\hline
\end{tabular}

Micro-Model. In an effort to make this model more accurate and reliable, we introduce a weighted index, and determine the weighs via AHP. Our target layer is the water supply ability in a region, criterion layer includes water quality, resources, and engineering. Then we subdivide water quality into underground water and surface water, and divide resources into industrial, agricultural and domestic water footprints. For engineering, we divide it into water from dams and sewage treatment. The classification is shown as Fig. 1.

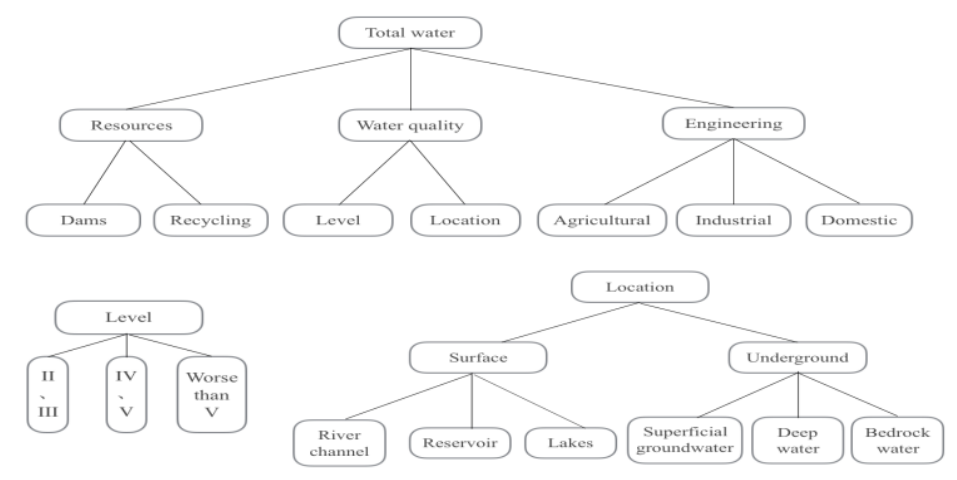

Figure 1.

Next, we build a judgment matrix to work out the weighs. Later, with each item's score, we get the results:

The standard for score is based on following factors:

Water quality: the proportion of each kind of water of total amount.

Resource: industrial, agricultural, domestic water resources' proportion of each type of water resources in the world. 
Engineering: reservoir water quantity proportion of total water resources and the reuse rate of sewage.

\section{Application of the Model in Beijing}

We choose Beijing for further study.

As we all know, water shortage in Beijing has been of long standing, including water qualityinduced water shortage, resources water shortage and engineering water shortage.

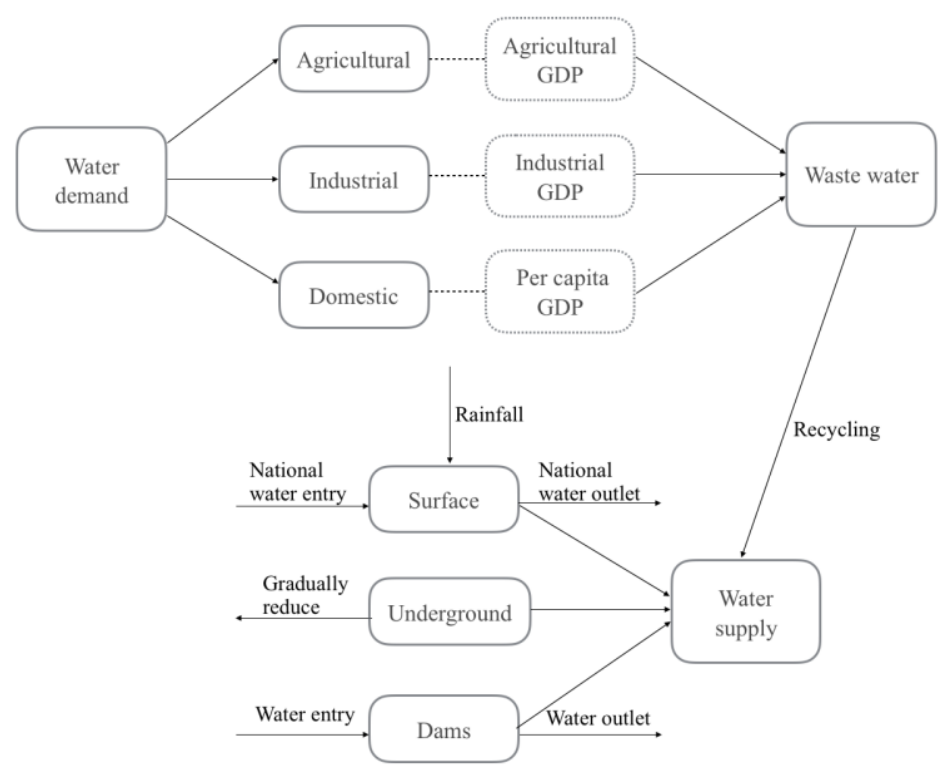

Figure 2.

First, we analyze the structure of water resource in Beijing, the details can be seen in Fig. 2 .

Macro-Model. We can calculate the water supply ability of Beijing, $\mathrm{A}=-0.8518$

Simulating Macro-Model, we discuss the values of population, GDP, rainfall, water storage. Through Grey Forecasting Model, and we count out the correlation degree between ability and other factors (rainfall, GDP, population, water storage) is $0.7417,0.6188,0.5584,0.5363$ respectively.

Therefore, we find population affects the water supply ability to a large extent.

Micro-Model. Through AHP, we work out the following table:

Table 2

\begin{tabular}{|c|c|c|c|}
\hline Water quality & Resources & Engineering & Total score \\
\hline 0.37359 & 0.0468 & 0.14566 & 0.56605 \\
\hline
\end{tabular}

In this course, we think that the higher item's score is, the more influence this item has on water supply ability.

Via this standard, we find the score of resource is low in Beijing, which illustrates Beijing is short of water resources.

There are lots of reasons accounting for this phenomenon. The most critical factor is large population in Beijing, which directly leads to great demand for water. Meanwhile, on account of economic development, the amount of freshwater needed will increase even rapidly. 
Impacts on Citizens' Lives. The shortage of water has an enormous impact on residents' daily life. Firstly, water scarcity leads to a reduction in crop yield. Secondly, it will constrain economic development to a large extend. Thirdly, people drink polluted water contaminated with various poisonous substances, which does harm to residents' health. Lastly, diseases can be spread easily under this severe condition.

\section{Intervention Plan of Water Resource}

According to our model, we find that the amount of water using for agriculture, industry and family is closely related to water demand, and the recycling of water also accounts for a high proportion of water supply. With the rapid urbanization and industrialization, lots of waste water is discharged into ecological system. What's more, water pollution will inevitably impact the surrounding areas, as well as the entire water ecosystem.

Besides, The availability of water also depends on environment, as well as several social factors, such as poor management and lack of infrastructure.

However, we think that the most effective way to solve water issue is to rise the number of dams.

Plan. Ignoring the impacts of geographical location, and keeping the total amount of water unchanged, we plan to build a new dam in Beijing.

In order to optimize this dam projection, we primarily use target regression. Our major goal is to mitigate water scarcity in Beijing, namely improving water availability. And minor aim is to minimize the investment. In this process, we define some variables: the quantities of water diversion from other region, water diversion from other dams in Beijing, underground water withdrawal and surface water withdrawal. Then we use those variables to find constraint conditions.

Finally, we work out an optimal solution:

The water supply of this new dam is 0.6132 billion cubic meters, including 0.083 billion cubic meters from other region, 0.061 billion cubic meters from dams in Beijing, 0.053 billion cubic meters from underground water and 0.087 billion cubic meters from surface water.

Strengths and Weaknesses of the Plan. Building more dams is a feasible intervention plan. It helps to provide high-quality source water and well-regulated flow, which can not only lead to an increase in supply of water directly, but also generate social and environmental benefits.

Whereas, there is no denying that this method has some negative effects. Many old cultural heritages are submerged due to this project. In a larger context, because river be blocked by dam, agriculture residue, and industrial pollutant cannot flow into the sea, resulting in more water pollution, and some areas even appear water bloom. Thus, the surrounding ecological environment might be worse.

\section{Conclusion}

Bringing our data into Macro-Model, and carrying out our intervention plan, we find that the annual water supply in Beijing will increase by $2.24 \%$.

With no intervention, the ability of Beijing to provide clean water to meet the needs of its population, namely $A$, equals to -2.733 , while with our intervention, $A=-2.6601$. Obviously, the water provision ability is improved through our plan, but Beijing is still short of water.

\section{References}

[1] Models, Methods, Concepts and Applications of the Analytic Hierarchy Process (with L.G. Vargas), Kluwer Academic Publishers, Boston, 2000.

[2] Charnes, A., Cooper, W.W., 1961. Management Models and Industrial Applications of Linear Programming, vol. 1. Wiley, New York. (Chapter 6, Appendix B, Basic Existence Theorems and Goal Programming)

[3] Fuzzy Sets and Systems - Theory and Applications, Academic Press, New York (1980) 
[4] Multiple objective decision making methods and applications. In: Fandel, G., Gal, T., Hanne, T. (Eds.), Lectures Notes in Economics and Mathematical Systems 164. Springer, Berlin

[5] FENG zhi-ming, A Study on Water Resources Carrying Capacity in Jingjingji Regin.JOURNAL OF NATURAL RESOUCES Vol.21 No.5 Sp,2006

[6] FAN Ying-ying. Forecasting and analysis of balance between water resources supply and actual demand in Beijing City Journal of Safety and Enviroment Vol.6 No.1 Feb, 2006

[7] AQUASTAT. Food and Agriculture Organization of the United Nations. FAO Water Resources. (http://www.fao.org/nr/water/aquastat/water_res/index.stm).

[8] http://www.cquc.net/e/action/ShowInfo.php?classid=25\&id=37607

[9] http://cpfd.cnki.com.cn/Article/CPFDTOTAL-HJKP200705001071.htm

[10] http://www.njliaohua.com/lhd_6o98m0jma23y3j84w1kt_1.html 